DÉNES ZOLTAI

ETHOS UND AFFEKT 



\section{DÉNES ZOLTAI}

\section{ETHOS UND AFFEKT}

GESCHICHTE DER PHILOSOPHISCHEN MUSIKÄSTHETIK VON DEN ANFÃGEN BIS ZU HEGEL

AKADEMIE - VERLAG - BERLIN

AKADÉMIAI KIADÓ - BUDAPEST

I 970 
Titel det-ungarischen Ausgabe: A zeneesztétika története I. Ethosz is affektus Zenemúkiadó Vallalat, Budapest 1966

\author{
Ưbersetzung von \\ BÉLA WEINGARTEN \\ Lektor \\ ARPÁD SZABÓ \\ Deutsche Bearbeitung \\ von \\ HEINZ PEPPERLE \\ und \\ KATHARINA OCHSENREITER \\ Institut für Philosophie \\ der \\ Deutschen Akademie der Wissenschaften \\ Berlin \\ sowie \\ FRANK SCHNEIDER \\ Zentralinstitut für Musikforschung \\ Betlin
}

(C) 1970 by Akadémiai Kiado, Budapest

Der Vertrieb dieses Exemplars ist nur in der Deutschen Demokratischen Republik, der Deutschen Bundesrepublik und Westberlin, der Schweiz und in Osterreich gestattet.

Erschienen im Akademie-Verlag GmbH, 108 Berlin, Leipziger Straße 3-4, in Arbeitsgemeinschaft mit dem Akadémiai Kiadó, Budapest V., Alkotmány u. 21 .

Lirenznummer: 100/231/70 Bestellnummer: $5805 \cdot$ ES 3 B 4 Preis: 25, - M 